\title{
EXTENSÃO POPULAR: CONCEITO, HISTÓRIA E PERSPECTIVAS*
}

\author{
Pedro José Santos Carneiro Cruz \\ Renan Soares de Araújo
}

\begin{abstract}
[...] legítima raiva, que envolve o meu discurso quando me refiro às injustiças a que são submetidos os esfarrapados do mundo. Daí o meu nenhum interesse de, não importa que ordem, assumir um ar de observador imparcial, objetivo, seguro, dos fatos e dos acontecimentos. Em tempo algum pude ser um observador "acizentadamente" imparcial, o que, porém, jamais me afastou de uma posição rigorosamente ética. Quem observa o faz de um certo ponto de vista, o que não situa o observador em erro. 0 erro na verdade não é ter um certo ponto de vista, mas absolutizá-la e desconhecer que, mesmo do acerto de seu ponto de vista é possível que a razão ética nem sempre esteja com ele. $O$ meu ponto de vista é o dos "condenados da Terra", o dos excluídos [...] (FREIRE, 1996, p. 16).
\end{abstract}

\section{Introdução}

Desde os seus primórdios, a universidade tem sido berço da construção teórica de muitas propostas e formulações críticas e reflexivas sobre o seu fazer e, consequentemente, sobre seu ethos e seu papel social. Assim, ao tempo em que seus/suas protagonistas historicamente sempre se ocuparam das atividades de ensino (preponderantemente), de pesquisa científica e de ação social pela extensão, muitos desses atores e atrizes também empreenderam e continuam a depreender esforços no sentido de pensar a instituição universitária, contextualizando - em cada tempo - seus desafios e suas contribuições para as demandas sociais.

Esse processo de pensamento vem acompanhado da explicitação de concepções, de ideias, de metodologias e de pressupostos teóricos que alimentam distintos debates sobre a universidade. Além de inspirar, mobilizar e orientar diferentes modelos de abordagem no âmbito do ensino, da pesquisa e da ação social lideradas por diversos/as protagonistas (docentes, discentes e técnicos).

*DOI - 10.29388/978-65-86678-84-0-0-f.25-42 
No campo pertinente aos conceitos, às reflexões, aos aspectos metodológicos e às perspectivas teóricas alinhados com a busca do fortalecimento de uma concepção cidadã e democrática de universidade, certamente seria possível elencar vários exemplos. Dentre esses, a Universidade Popular, a Pesquisa-ação, a Pesquisa Participante, a Sistematização de Experiências e tantos outros. Não obstante, para os autores do presente ensaio, nos últimos 30 anos, um dos principais conceitos a emergir no debate universitário brasileiro, tendo sua origem na região nordeste, consiste na Extensão Popular.

Em virtude do exposto, no presente manuscrito, buscamos situar tendo como base a experiência de uma comunidade de trabalho constituída a partir de um grupo de pesquisa e de um coletivo de amplitude nacional mesmo que brevemente, alguns aspectos teóricos que julgamos centrais para a compreensão do conceito de Extensão Popular e sua historicidade, assim como explicitamos uma questão considerada como significativa para o (re)pensar e o (re)fazer das práticas extensionistas alinhadas com essa concepção, qual seja: a necessidade de decolonizar a extensão universitária e a produção de conhecimento.

\section{Uma visão panorâmica sobre o conceito de Extensão Popular e sua historicidade}

Por Extensão Popular, estamos nos referindo a uma concepção teórico-prática de Extensão Universitária orientada pela perspectiva teórico-metodológica da Educação Popular. Em todo o Brasil, são diversos os projetos, os programas e os coletivos que se identificam com esse conceito e o utilizam como expressão de suas intencionalidades políticas e pedagógicas quando da promoção de suas ações extensionistas.

Esse amplo movimento de práticas extensionistas populares é antigo, mas adquiriu maior identidade e expressividade nacional, em especial, a partir dos anos 2000, sobretudo após a criação da Articulação Nacional de Extensão Popular (ANEPOP) em 2005 e em decorrência da promoção frequente dos Seminários Nacionais de Pesquisa em Extensão Popular (SENAPOP), realizados pelo Grupo de Pesquisa em Extensão Popular (EXTELAR) da Universidade Federal da Paraíba (UFPB) em parceria com a ANEPOP, que já lograram êxito em fomentar três edições desse evento, respectivamente nos anos de 2009, 2013 e 2016. 
Pode-se então situar que, no âmbito universitário, a Extensão Popular constitui um referencial ético, político, teórico e metodológico a partir do qual diversos grupos de estudantes, docentes, técnicos e outros atores e atrizes sociais se mobilizam para construir trabalhos de pesquisa, de ensino e de ação social em um processo de comunicação intensa com a realidade concreta e suas multifacetadas determinações.

Esse processo, pela Extensão Popular, tem, tão somente, como seu ponto de partida o mergulho profundo na realidade social, com as suas alegrias, as suas dores, os seus desconfortos, as suas crises, as suas contradições e os seus processos dinâmicos e complexos. Tão somente a partir desse mergulho - continuado por uma convivência permanente com essa realidade - é que a Extensão Popular permitirá aos/às seus/suas protagonistas o desvelamentos de questões para a pesquisa e de temas uteis para o ensino e a aprendizagem, os quais subsidiarão a necessidade de intervenção nas distintas realidades para assim ser possível transformá-las.

A Extensão Popular é hoje, também, um símbolo identitário para aquelas experiências universitárias onde, pelo trabalho compromissado com as classes populares, aprende-se a ser mais - como delineado por Freire (2013) - e a construir uma aplicação da ciência que seja edificante, consequente, dialógica e emancipadora. Por meio da identificação por Extensão Popular, os/as protagonistas de diferentes experiências Brasil afora se encontram, se reconhecem e se fortalecem na busca pelo constante aprimoramento de suas realizações. Além disso, na determinação incessante em alimentar a Extensão Popular como um movimento que não se contenta em ser apenas expressivo em variadas práticas locais, mas sobretudo na proposição de debates, reflexões e provocações para se repensar a estrutura da universidade como um todo, inclusive na reorientação de sua concepção de "compromisso social".

As atividades de Extensão Universitária promovidas de forma alinhada com os preceitos da concepção latino-americana de Educação Popular (na acepção freiriana do termo) remontam aos anos de 1940 no Brasil (tendo suas raízes históricas ainda bem mais anteriores). Então, podese dizer que a Extensão Popular existe, no contexto brasileiro, há aproximadamente oito décadas. Com esse sentido, é especialmente desde meados da década de 1990 que se expandem país afora experiências de Extensão orientadas pela concepção da Educação Popular.

Em uma conjuntura de relativa estabilidade do ponto de vista republicano e democrático, com paulatino estabelecimento de um Estado pau- 
tado por políticas públicas e com ênfase nas políticas sociais, após duas décadas de Ditadura Militar, o Brasil passou a ter um ambiente propício para a proposição de abordagens capazes de orientar o agir público em cenários de adversidade socioeconômica, bem como para a elaboração de estratégias metodológicas que possibilitassem o enfrentamento dos processos de exclusão social. Nessa década, difundem-se progressivamente, por exemplo, as Organizações Não Governamentais (ONGs) e passam a adquirir mais valorização as atividades de Extensão Universitária.

O aparente "clima democrático" e a participação ativa dos movimentos sociais nos processos de embates e conquistas populares, favoreceram a pressão de vários segmentos sociais e acadêmicos para que a instituição universitária abandonasse a sua posição de neutralidade diante de toda essa efervescência e passasse a dialogar com esses setores, com vistas a fortalecê-los e a aperfeiçoar sua capacidade de lutar pela garantia de direitos e a conquista de cidadania.

À medida que se caminhava nesse percurso inicial de vivência republicana - nos termos da "Constituição Cidadã", promulgada no ano de 1988 -, evidenciava-se que era preciso uma nova postura para a vida em sociedade. Por esse ângulo, a universidade - como instituição social - não poderia ficar alheia a todo esse processo. Até mesmo porque muitos daqueles grupos (estudantis e docentes) - antes relegados aos trabalhos subversivos e à clandestinidade no contexto da Ditadura Militar (19641985) - finalmente poderiam pautar suas experiências acadêmicas de trabalho social no seio das classes populares de forma pública.

Dentro de muitas dessas experiências, a partir das potencialidades da proposta de ação político-pedagógica da Educação Popular - expressa de maneira profusa em toda a obra freiriana -, especialmente no que diz respeito à composição de um agir social e profissional emancipatório e humanizador, várias iniciativas de atuação extensionista universitária passaram a buscar guiar seus passos em acordo com seus preceitos teóricometodológicos.

Assim, processualmente, organizaram-se diferenciadas práticas extensionistas assumidamente pautadas por um caráter popular no âmbito acadêmico, e dessas emergiram desdobramentos com movimentos e com organizações de coletivos que passaram a reivindicar e propor conjuntamente o fortalecimento e a consolidação institucional desse agir extensionista popular, por meio de uma perspectiva ético-política que 
pudesse arrolar, também, a mudança da atuação universitária em sua integralidade.

Em meio a esse efervescente quadro, enquanto formulação teóricometodológica, pode-se situar sua origem no final de 1990 e no contexto da UFPB, pois em sua tese de doutoramento na Universidade de Brasília (UnB), concluída em 1996 e intitulada Extensão universitária: uma análise crítica, José Francisco de Melo Neto empreendeu uma pesquisa com acompanhamento sistemático de diferentes projetos e programas de extensão universitária institucionalmente vinculados à UFPB e, ancorandose na categoria trabalho, apontou a necessidade de se ampliar a conceituação da Extensão como forma de superar a noção amplamente difundida e predominante da prática extensionista como uma "via de mão dupla", como o fizera à época o hoje denominado Fórum de Pró-Reitores/as de Extensão das Instituições Públicas de Educação Superior Brasileiras (FORPROEX):

[...] uma via de mão dupla, com trânsito assegurado à comunidade acadêmica que encontrará, na sociedade, a oportunidade de elaboração da práxis de um conhecimento acadêmico. No retorno à universidade, docentes e discentes trarão um aprendizado que, submetido à reflexão teórica, será associado àquele conhecimento. Esse fluxo estabelece a troca de saberes sistematizado, acadêmico e popular (FORPROEX, 2007, p. 12).

No entanto, os estudos executados por Melo Neto (1996; 2002; 2004; 2014) o fizeram perceber a constituição processual de uma nova formulação conceitual da Extensão, caracterizada como um trabalho social útil.

Trabalho por pressupor que a partir da execução desse labor, que resultará em uma ação deliberada, será possível obter um produto, o qual poderá ser dirigido e utilizado com a ótica de possibilitar transformações pelo fato de que é por meio do trabalho que o ser humano intervém no mundo, criando cultura e modificando a sua realidade na construção de um mundo que poderá ser, efetivamente, mais propício para os seres humanos viverem (MELO NETO, 1996).

Em consequência, a atividade extensionista é concebida como trabalho social por compreender que essa não é algo meramente contemplativo do mundo; mas sim como uma ação de interação com a natureza (entre os sujeitos e a realidade objetiva) que resulta na elaboração 
de um produto que será pertencente a todos os indivíduos envolvidos em seu processo de produção, como ato coparticipado que se realiza de modo biunívoco, inviabilizando a possibilidade de sua alienação (MELO NETO, 2002; 2014).

Não obstante, essa acepção da Extensão como trabalho social precisa estar atrelada a alguma utilidade produtiva que beneficie de alguma forma a vida das pessoas. Portanto, é imprescindível que tal utilidade se expresse como forma de corresponder aos anseios da existência humana e às suas buscas por felicidade e pela factual possibilidade de não apenas sobreviver, mas de viver uma vida que seja verdadeiramente digna e plena (MELO NETO, 2004; 2014).

$\mathrm{Na}$ verdade, pode-se sumariar que, para Melo Neto (2014), a Extensão trata-se de um trabalho social e útil. Ou, melhor dizendo:

Extensão, como trabalho social útil com a intencionalidade de conectar o ensino e a pesquisa, passa a ser agora exercida pela universidade e por membros de uma comunidade sobre a realidade objetiva. É, portanto, um fenômeno educativo com um conteúdo pedagógico derivado de questões da realidade social. Também é prestadora de serviço sem ter essa finalidade. Pode, ainda, realizar alguma assistência sem se tornar uma política compensatória assistencial. Como ensino, é difusora de conhecimento bem como capturadora de problemas científicos, artísticos, técnicos e culturais da sociedade, contribuindo para que sejam analisados pelas técnicas de pesquisa, em especial metodologias de pesquisa que promovam a participação, a exemplo da pesquisa-ação. Um trabalho coparticipado que traz consigo as tensões de seus próprios componentes em ação e da própria realidade objetiva. Um trabalho de construção do conhecimento novo ou reformulações das verdades existentes. Esses objetos pesquisados serão os constituintes de outra dimensão da universidade: o ensino. É também um trabalho de busca de objeto para a pesquisa. A extensão configura-se e concretiza-se como trabalho social útil, imbuído da intencionalidade de pôr em mútua correlação o ensino e a pesquisa. Portanto, é social na medida em que não será uma tarefa individual; é útil, considerando que esse trabalho deverá expressar algum interesse e atender a uma necessidade humana. É, sobretudo, um trabalho que tem na sua origem a intenção de promover o relacionamento entre ensino e pesquisa. Nisto, e fundamentalmente nisto, diferencia-se das dimensões outras da universidade, tratadas separadamente: o ensino e a pesquisa (MELO NETO, 2014, p. 46). 
Como exposto, esse conceito vislumbra a concepção de Extensão como produto de um esforço criativo desenvolvido entre a universidade e a sociedade, "não como entes separados, mas em relação permanente entre si e que, nem por isso, deixam de se diferenciar" (MELO NETO, 2004, p. 54). Fazendo também uma análise do que seja "popular" na concepção de lideranças de diferentes movimentos sociais, membros de sindicatos e partidos políticos de corte progressista, Melo Neto (2014) conceitua o que seria uma Extensão Popular e elenca as suas dimensões constituintes, com especial destaque para elementos como a origem e o direcionamento dessas ações, a explicitação de seu papel e de seu horizonte político, bem como a relevância do uso de estratégias metodológicas promotoras do diálogo:

Ao assumir a dimensão do popular, o conceito de extensão passa a considerar as dimensões fundantes do adjetivo como a origem e o direcionamento das questões que se apresentam; o componente político essencial e norteador das ações; e, com especial destaque, o popular expresso por metodologias que apontem encaminhamentos de ações, acompanhadas de seus aspectos éticos (diálogo, solidariedade, tolerância, coletivo...) e utópicos (autonomia, liberdade...) que, para os dias de hoje, tornam-se uma exigência social. Assumindo a dimensão do popular, a extensão transpõe os muros institucionais, superando o seu exercício resumido apenas a ações de participantes de determinadas organizações sociais, sobretudo estatais. Adquire, como trabalho social, a dimensão de exterioridade, abrangendo ações educativas em movimentos sociais e outros instrumentos organizativos da sociedade civil, ou mesmo a partir do Estado. Como trabalho social útil com a intencionalidade de transformação, direcionado aos setores sociais excluídos, a extensão popular realiza-se no conjunto das tensões de seus participantes em ação e da realidade objetiva. Nesta perspectiva, a extensão popular contém uma metodologia de trabalho social que desenvolva uma visualização maior das contradições do modo de produção dominante, mesmo que os trabalhadores tenham pouca escolaridade e baixa qualificação, elementos promotores de exclusão, sobretudo nesses setores sociais (MELO NETO, 2014, p. 47-48).

Nessa direção, é possível compreender a Extensão Popular como um trabalho que é social e útil, sendo necessariamente desenvolvido por meio de um agir crítico que se dá a partir de um processo em cujas bases 
estão, essencialmente, a construção, a participação e o compartilhamento. Esse trabalho assume, para seus protagonistas e para a exterioridade de sua experiência, uma intencionalidade política, a qual se expressa cristalinamente com base em duas dimensões: i) a busca de articular tanto o ensino como a pesquisa na mobilização de experiências, estudos e reflexões em meio a contextos marcados por situações de adversidade; ii) a superação de problemas sociais de maneira compromissada com a mudança e o enfrentamento à exclusão social e à desumanização.

A despeito disso, é importante salientar que em realidade o que se sucedeu foi que o trabalho teórico desenvolvido por Melo Neto oportunizou o incremento e suscitou melhor suporte teórico-metodológico para um conjunto de experiências já vinham sendo exercidas por diferentes grupos extensionistas em diversas regiões e territórios espalhados pelo Brasil. O que denota que esse processo de caracterização do conceito de Extensão Popular não principia de forma isolada, mas aflui a partir de um duplo movimento, que engloba tanto a sistematização de Melo Neto quanto as inquietações e reflexões efetivadas por outras pessoas e coletivos imbrincados com as atividades extensionistas.

Com isso, demonstra-se que toda essa dinâmica se expressou como elemento propulsor da qualificação e do fortalecimento das experiências extensionistas que se identificavam com o conceito de Extensão Popular, que como assinalado por Cruz (2010), consistiam de atividades precedentemente empreendidas, as quais, muitas vezes, careciam de aportes mais sistematizados em sua fundamentação, sobretudo em suas dimensões filosófica e teórico-metodológica, o que contribuiu para sua autoavaliação crítica e para a (re)orientação e (re)qualificação de suas práticas.

Especialmente a partir da década dos anos 2000, passa-se cada vez mais a vislumbrar espaços para diversas experiências extensionistas inovadoras que insistam no potencial libertador da educação e na necessidade de que a instituição universitária instaurasse diálogo com a sociedade, sobretudo com os setores populares. Assim, paulatinamente as vivências de Extensão em Educação Popular encetaram a ser incluídas na estrutura curricular e organizacional da universidade, que apesar de ainda permanecer preeminentemente conservadora - como reflexo das contradições da sociedade que conforma parte -, passou a abarcar ações de caráter progressista.

Esse movimento emerge igualmente da percepção de muitos/as extensionistas quanto a certa elitização do movimento de Extensão liderado 
por dirigentes universitários/as - como os/as pró-reitores/as -, os/as quais mantinham um papel central quanto a definição e o aperfeiçoamento conceitual da Extensão, bem como da mobilização de sua articulação com as políticas públicas e com o fortalecimento dessa atividade no âmbito acadêmico, mas que também pouco abriam o movimento em defesa da Extensão para a participação estudantil, docente e de técnicos. Ademais, ao passo em que defendiam uma visão progressista da Extensão, pouco enfatizavam a centralidade de alguns de seus elementos, como a emancipação, a problematização, a construção metodológica compartilhada, a valorização dos sujeitos populares como protagonistas, o diálogo intercultural, entre outros.

O incomodo de muitos/as protagonistas de iniciativas de Extensão Popular com a forma como os/as pró-reitores/as guiavam as políticas de extensão universitária teve um marco importante no ano de 2004, no contexto do Congresso Iberoamericano de Extensão, que foi realizado em um hotel luxuoso situado na Praia de Copacabana, no Rio de Janeiro-RJ, tendo como espaços centrais de fala momentos apenas atrelados a dirigentes universitários/as e alguns/algumas intelectuais acadêmicos/as. Nessa ocasião, foi ampliada, difundida e socializada coletivamente a insatisfação de muitos/as extensionistas populares de todo o país, os/as quais instigaram a realização das primeiras reuniões de articulação e de mobilização, inicialmente em torno de um primeiro importante espaço de diálogo e inter-relação, que foi a Ação Nacional de Extensão Universitária (ANEXU).

Nesse período, outro fenômeno que confluiu para a irradiação da Extensão Popular no território brasileiro foi em decorrência do crescente número de eventos nacionais e regionais que se configuravam como espaço de encontro para os/as extensionistas. Oportunizado, precipuamente, devido a criação do Congresso Brasileiro de Extensão Universitária (CBEU), que teve sua primeira edição ocorrida no ano de 2001, na cidade de João Pessoa-PB, com a sua segunda edição transcorreu no ano de 2004, na cidade de Belo Horizonte-MG. Desde então, desenrolou-se a consecução sistemática de espaços e momentos de encontros, permitindo uma comunicação com certa regularidade entre os/as extensionistas populares que, ao perceber o contexto hegemônico no campo da Extensão Universitária brasileira - que se materializava fortemente nas edições do CBEU -, passaram a buscar mecanismos que proporcionassem uma organização interna mais apurada, com o intuito de reivindicar melhoramentos no cenário institucional e avigorar a Extensão Popular. 
Encontro após encontro, outro incomodo observado e que inquietou sobremaneira os diversos membros de vários projetos e programas de Extensão Popular de todo o país, foi derivado da forma como os CBEU eram organizados, os quais retratavam os modelos de Extensão predominantes, marcados pelo elitismo acadêmico e por abordagens de cunho assistencialista ou mercantilista. Com isso, os atores e atrizes sentiam, cada vez mais, a necessidade de priorizar a sua estruturação organizativa e qualificar sua reivindicação por mudanças, o que justificava como essencial a manutenção de uma comunicação permanente e a possibilidade de interagir e trocando experiências.

Todo esse contexto possibilitou o crescimento de um movimento nacional que insistiu na perspectiva popular de Extensão e que passou a ser defensor da democratização da organização nacional das políticas de extensão universitária. De modo que esse movimento culminou com a criação da Articulação Nacional de Extensão Popular (ANEPOP), em dezembro do ano de 2005, após a sequência de encontros entre os/as diversos/as extensionistas populares, técnicos, trabalhadores/as de saúde e educação e membros de movimentos populares no II Seminário Nacional de Educação Popular em Saúde, que foi realizado em Brasília-DF. Assim, formada por professores/as, técnicos, estudantes e membros de movimentos populares insatisfeitos com o atual modelo de formação universitária, a ANEPOP foi criada com vistas a fortalecer os princípios da concepção freiriana da Educação Popular nas ações acadêmicas a partir da Extensão.

Especialmente entre os anos de 2005 e 2016, a ANEPOP procurou criar canais de comunicação que tornassem possível a troca de experiências, ideias e reflexões entre os atores e atrizes envolvidos/as com iniciativas de Extensão Popular. Destarte, para alicerçar as suas bases e permitir a construção do movimento, seus atores e atrizes procuraram apostar na força do trabalho coletivo e valorizar os encontros presenciais que eram viabilizados e socializados por meio de redes sociais virtuais de comunicação.

No entendimento dos autores deste ensaio, a ANEPOP consistiu um movimento instituinte de uma nova abordagem integradora da vida universitária com os movimentos sociais, fundamentada no diálogo entre as dimensões do pensar e refletir sobre a Extensão em uma perspectiva progressista, sustentando-se também na insatisfação com a forma como o CBEU e as demais instâncias de debates vinham sendo geridas e 
estruturadas, assim como em consequência da situação de total desvalorização da participação de estudantes, professores/as, profissionais e movimentos sociais na elaboração das políticas de extensão universitária.

\section{Extensão Popular: decolonizar a extensão universitária e a produção do conhecimento}

É relevante salientar que a partir da Extensão Popular se sobressai a perspectiva de superação da compreensão tradicional da Extensão como hegemonicamente foi sendo desenvolvida pelas universidades, de maneira colonizadora, por meio de um movimento que se desenrola de dentro da instituição universitária para seu exterior, em uma ótica de dominação e invasão cultural, como muito bem assinalou Freire (2015) ao enfatizar a necessidade que certos grupos extensionistas sentiam (e ainda sentem) de ir até determinadas comunidades consideradas por eles ou elas como "carentes", "atrasadas", "incivilizadas" e ao/à seu modo modernizá-las, se autoconcebendo como os/as seus/suas redentores/as.

Como referido por Santos (2019), as instituições universitárias ocidentais (ou, em alguns casos, ocidentalizadas), ao longo dos séculos, têm servido de berçário para as epistemologias do Norte global, que são fundamentadas em uma racionalidade moderno/colonial e eurocentrada/ocidentalocêntrica, responsáveis pelo processo de depreciação, invisibilização e deterioração de outros conhecimentos e formas de racionalidade. O que denota, em acordo com Santos (2019), no epistemicídio de uma inesgotável diversidade de saberes e no desperdício de uma rica gama de experiências oriundos do Sul global, já que o paradigma científico hegemônico não é dotado de capacidade para compreender e se articular com os conhecimentos elaborados pelos diferentes sujeitos e grupos (indígenas, negros/as, mulheres, camponeses/as etc.) que há muito tempo vêm sendo alvo dos processos de exclusão, de opressão e de dominação que fundamentam e estruturam o modelo ocidental de sociedade a partir dos seus três eixos: o capitalismo, o colonialismo e o patriarcado.

Diante disso, pela abordagem da Extensão Popular evidencia-se que é necessário (re)pensar e questionar o colonialismo científico e a posição que tem estabelecido o conhecimento acadêmico-científico como uma 
"verdade universal" ou a "hybris ${ }^{11}$ do ponto zero", como delineado por Castro-Gómez (2007) - ao criticar o modelo epistemológico que impera no seio das universidades latino-americanas e que estrutura-se com base em um "olhar moderno/colonial" sobre o mundo. Segundo Castro-Gómez (2007), é essa ideia que dá sustentação a falsa noção de que o conhecimento científico é produzido de forma apartada do mundo, como se o pesquisador e a pesquisadora observassem o mundo de fora dele (o ponto zero), situando-se em uma espécie de plataforma de observação que é inobservável, o que Ihes permitiria alcançar um forma de observação fidedigna, neutra e inquestionável da realidade.

Esse pensamento moderno/colonial, se firma com base na desvalorização e inferiorização das outras formas de saberes existentes, o que evidencia e alimenta a hegemonia de uma racionalidade eurocêntrica e colonial, que se expressa como cunhado por Quijano (2009), em forma de colonialidade, nesse caso, a colonialidade do saber.

Para Quijano (2009), colonialidade se distingue de colonialismo justamente por possuir como parte intrínseca de sua característica raízes mais profícuas e duradouras, que possibilitaram a manutenção da matriz colonial do poder, ainda que tenha ocorrido o desfecho do colonialismo político. A colonialidade se alicerça articulando a categoria "raça" como dispositivo de distinção, hierarquização e dominação dos diferentes sujeitos e grupos socioculturais, desumanizando-os, inferiorizando-os e subalternizando-os em relação aos colonos brancos/europeus que são o exemplo maior e fiel da superioridade, modernidade e civilidade que precisa ser estendida a todos os povos e territórios, o que justificou a sua imposição por meio da força e da violência.

Conforme Walsh (2012), a colonialidade do saber se fundamenta na alegação de que a racionalidade e a produção de conhecimentos são atributos facultados unicamente aos sujeitos de origem europeia, ignorando e excluindo a existência de outros tipos de racionalidades e menosprezando todos os outros modos de se produzir saberes, sobretudo os saberes procedentes dos povos e das comunidades autóctones, ao empregar universalmente como parâmetro epistemológico a modalidade

\footnotetext{
${ }^{1}$ Conforme Castro-Gómez (2007, p. 83): “Cuando los mortales quieren ser como los dioses, pero sin tener capacidad de serlo, incurren en el pecado de la hybris, y esto es, más o menos, lo que ocurre con la ciencia occidental de la modernidad. De hecho, la hybris es el gran pecado de Occidente: pretender hacerse un punto de vista sobre todos los demás puntos de vista, pero sin que de ese punto de vista pueda tenerse un punto de vista".
} 
de racionalidade de cunho eurocêntrico/colonial/moderno, que se consubstancializa na efígie da ciência moderna.

Para decolonizar a Extensão Universitária, se faz crucial ter em vista o que aponta Mignolo (2017), ao indicar que o pensamento decolonial se alicerça no esforço constante por desvelar e apreender a organização e o funcionamento da matriz moderna/colonial e eurocêntrica, com o intuito de despegar-se e desaproximar-se das "visões" da modernidade e de suas tramas coloniais, com a ótica de viabilizar a sua superação e a composição de projetos decoloniais.

A decolonialidade no âmbito da Extensão Popular significa a busca e a provocação contínua pela adoção de uma posição teórica, política e epistemológica que aposta e se fixa em uma atitude de transgressão permanente e de crítica radical dos eixos estruturantes do projeto de civilização ocidental moderna/colonial e assim identificar e sinalizar outras possibilidades e caminhos para transformar as relações sociais, as instituições e as estruturas da sociedade como um todo, como expresso por Walsh (2009).

Em síntese, pode-se sinalizar que pela Extensão Popular parte-se dos seguintes pressupostos: a) não há conhecimento neutro/todo conhecimento é situado e implicado; b) o saber científico é uma entre outras formas de "conhecer" (que tem também a sua devida relevância); c) estabelece-se relações sujeito-sujeito e não sujeito-objeto; d) não visa "transferir" ou "depositar" conhecimentos, mas reconhecer e valorizar os saberes de experiência feito - como diria Freire (1996) - desses sujeitos e possibilitar a produção de novos saberes; e) apoiar e contribuir com os processos de transformação social.

Desde a Extensão Popular, o conhecimento é reconhecido como um produto situado, sendo o saber científico apenas uma amostra entre tantas outras formas de saber, que desvela unicamente um lado/leitura do fenômeno em questão e não a sua interpretação única e absoluta. Consubstanciando com tal entendimento, Oliveira (2018) reitera que a produção do conhecimento não se dá em uma "vazio" contextual e sem um direcionamento, sem uma perspectiva de projeto. Para essa autora, todo conhecimento é situado (em âmbito social, político e cultural) e apresenta uma intencionalidade, um horizonte a ser buscado.

Diante disso, Oliveira (2018) pontua que não passa de uma postura ilusória a do sujeito que indica ser politicamente neutra a ciência que o mesmo produz, como se a dimensão política do conhecimento só se fizesse presente em um uso posterior que alguma outra pessoa viesse a fazer de 
tal conhecimento. Na produção de conhecimento na perspectiva da Educação Popular, assume-se a não neutralidade da ciência e evidencia-se a intencionalidade política da pesquisa em seu compromisso com a apreensão da realidade social na busca de transformá-la, estando assim, fortemente vinculada com a noção de práxis.

Por esse ângulo, decolonizar, para a Extensão Popular, indica que é basilar que se compreenda que conhecimento algum se constitui de maneira isolada ou de forma autossuficiente. Os saberes se constroem de modo relacional e são complementares. Quanto mais diferentes modos de interrogar e interpretar a realidade estabelecerem inter-relações e diálogos horizontalizados, maior será a chance de se construir novos conhecimentos sobre a realidade.

Em razão disso, pela Extensão Popular busca-se superar a ideia que tem o trabalho extensionista como uma ação que visa "estender", "levar", "depositar" ou "transferir" um conjunto de conhecimentos às pessoas, mas sim que se propõe a possibilitar o encontro de diferentes sujeitos e o diálogo entre os seus saberes, o que viabiliza a produção de novos conhecimentos resultantes desse diálogo e da prática social. Dessa forma, é concebível a elaboração de um novo conhecimento resultante desse encontro e diálogo entre saberes distintos para a constituição do que Fleuri (2019) cognominou de conhecimento conversitário - que é um saber construído compartilhadamente que emerge como fruto de um diálogo crítico, participativo, conflitivo e propositivo entre a universidade e os movimentos sociais a partir de uma abordagem dialética, intercultural e política da práxis científica.

Por isso, para a Extensão Popular é imprescindível que o conhecimento seja construído de forma compartilhada, como forma de romper com a hegemonia e as amarras modernas/coloniais que concebem o saber científico como o único modo de conhecer socialmente válido e que estabelece a racionalidade científica como a detentora do direito de assinalar o que pode ser considerado como verdadeiro/falso, legítimo/ilegítimo, tangível/intangível, compreensível/incompreensível etc. Pela Extensão Popular parte-se da compreensão de que os sujeitos são singulares e que esses possuem distintos saberes, os quais que são resultantes de suas diferentes inserções e vivências culturais, as quais, por meio do estabelecimento de diálogos críticos e de mútuas interações, podem oportunizar momentos de ensino-aprendizados enriquecedores (FLEURI, 2019). 
Dentre as contribuições da decolonialidade para a Extensão Popular, assinalamos que é precípuo o reconhecimento da pluralidade dos sujeitos que compõem a expressão "popular" - ou, seria mais pertinente ainda aderirmos ao uso constante do seu plural (populares) -; para demarcar as especificidades presentes e constituintes das identidades de cada sujeito e grupo que estão contidos nessa locução, afastando-se das concepções que visam homogeneizar e obliterar as diferenças. Em relação a isso, o uso do plural não é mera predileção, mas a indicação de uma posição e do reconhecimento das diferentes identidades e características de todos os seres humanos "oprimidos", como assinalou Freire (2013), ou dos "condenados da Terra", como denunciou Frantz Fanon (1968).

Por isso é importante que a Extensão Popular seja compreendida como o direcionamento crítico à abordagem acrítica das dimensões colonial, moderna e eurocêntrica hegemônica no âmbito da ciência e no contexto universitário, que por meio do diálogo intercultural crítico, se propõe a estabelecer pontes de comunicação que permitam uma "convivência intercultural valorizando as diferenças como potencializadoras de relações sociais críticas e criativas entre os diferentes sujeitos sociais e entre seus respectivos contextos culturais" (FLEURI, 2019, p. 105).

\section{Considerações finais}

Nas últimas três décadas, no contexto de uma Constituição Cidadã, o campo da extensão universitária tem contribuído significativamente para a alimentação de um amplo e diversificado movimento nacional de experiências que remam na direção da configuração de um fazer universitário socialmente referenciado e politicamente orientado pela formação crítica das pessoas. Em especial nas últimas duas décadas, com uma sucessão importante de políticas públicas voltadas ao aprimoramento do ensino superior no Brasil, as ações extensionistas com esse perfil puderam ser apoiadas e assim seus desdobramentos puderam ser amplificados em escritos e em experiências compartilhados nos mais diferentes espaços de debate e de reflexão sobre a universidade, seus desafios e suas perspectivas.

Consideramos que, hoje, a Extensão Popular situa-se como uma das substanciais alternativas de constituição de subjetividades inconformistas no contexto das instituições universitárias públicas brasileiras. O envolvimento de estudantes, docentes e técnicos, em diálogo com 
protagonistas populares e sociais, com a complexidade da dinâmica social povoada de sofrimentos, opressões e muitas possibilidades de fascinante construção coletiva, pode incitar o despertar e motivar o afastamento progressivo da alienação individualista e consumista tão disseminada no âmbito da sociedade capitalista e que tão fortemente tem incidido sobre a juventude, como pontuado por Vasconcelos (2015).

Diante do quadro atual de (re)discussões profícuas no âmbito universitário, se faz premente enfatizar a relevância da Extensão Universitária como possibilidade de encontro e elo de comunicação dos/as acadêmicos/as com a realidade social, permitindo-lhes conhecer os/as protagonistas dos setores populares e modos de viver, de se relacionar e de (re)existir. São diminutas as possibilidades se fazer diferente na ação universitária se não se priorizar como ponto de partida o estabelecimento de um encontro sincero e efetivo dos/as estudantes com as pessoas e com o mundo concreto. E é por meio da Extensão que essa perspectiva poderá ocorrer.

Acreditamos na Extensão Popular como uma teoria em construção, que se firma no entendimento da Extensão como trabalho social útil, forjado no diálogo horizontalizado e na construção compartilhada, por isso mesmo, uma ação de caráter decolonial, pois a partir da Extensão Popular, desponta a constituição de um corpus teórico consciente da perspectiva colonial/moderna e eurocêntrica imperante no contexto universitário e que, em decorrência disso, buscar orientar o pensar e o fazer acadêmicos socialmente comprometidos (articulando juntamente o ensino e a pesquisa), em vista de efetivar uma mudança significativa em ambos os sentidos dessa relação que se estabelece entre a instituição universitária e a sociedade.

A Extensão Popular mobiliza sentidos, relações e ações de um trabalho empreendido por diversos atores e atrizes (pre)ocupados e empenhados em avultar e alcançar o horizonte de um mundo que possa ser matizado com as cores que retratem os valores da justiça, da equidade e da dignidade humana, o qual seja fundado em uma relação harmoniosa e cuidadosa entre todos os seres humanos e com a natureza. É dessa forma que a concepção de Educação Popular fortalece e evidencia a dimensão política tão necessária à Extensão Universitária, e que é inerente à Extensão Popular. 


\section{Referências}

CASTRO-GÓMEZ, S. Decolonizar la universidad: la hybris del punto cero y el diálogo de saberes. In: CASTRO-GÓMEZ, S.; GROSFOGUEL, R. (Comp.) El giro decolonial: reflexiones para una diversidad epistémica más allá del capitalismo global. Bogotá: Siglo del Hombre Editores, 2007. p. 79-91.

CRUZ, P. J. S. C. Extensão popular: a pedagogia da participação estudantil em seu movimento nacional. 2010. 339 f. Dissertação (Mestrado em Educação) - Centro de Educação, Universidade Federal da Paraíba, João Pessoa, 2010.

FANON, F. Os condenados da Terra. Tradução de José Laurênio de Melo. Rio de Janeiro: Civilização Brasileira, 1968.

FLEURI, R. M. Conversidade: diálogo entre universidade e movimentos sociais. João Pessoa: Editora do CCTA, 2019.

FÓRUM DE PRÓ-REITORES DE EXTENSÃO DAS UNIVERSIDADES PÚBLICAS BRASILEIRAS - FORPROEX. Extensão universitária: organização e sistematização. Belo Horizonte: Coopmed, 2007.

FREIRE, P. Extensão ou comunicação? 17. ed. São Paulo: Paz e Terra, 2015.

FREIRE, P. Pedagogia do oprimido. 50. ed. Rio de Janeiro: Paz e Terra, 2013.

FREIRE, P. Pedagogia da autonomia: saberes necessários à prática educativa. São Paulo: Paz e Terra, 1996.

MELO NETO, J. F. Extensão popular. 2. ed. João Pessoa: UFPB, 2014.

MELO NETO, J. F. Extensão universitária é trabalho. João Pessoa: UFPB, 2004.

MELO NETO, J. F. Extensão universitária: bases ontológicas. In: MELO NETO, J. F. (Org.). Extensão universitária: diálogos populares. João Pessoa: UFPB, 2002. p. 7-22. 
MELO NETO, J. F. Extensão universitária: em busca de outra hegemonia. Revista de Extensão, João Pessoa, ano. 1, n. 1, p. 9-21, jul. 1996.

MIGNOLO, W. D. Colonialidade: o lado mais escuro da modernidade. Rev. bras. Ci. Soc., São Paulo, v. 32, n. 94, e329402, 2017. Disponível em:

http://www.scielo.br/scielo.php?script=sci_arttext\&pid=S010269092017000200507\&lng=en\&nrm=iso. Acesso em: 25 abr. 2020.

OLIVEIRA, M. W. Lugares e intencionalidades no que fazer da pesquisa. In: CRUZ, P. J. S. C. (Org.). Educação popular em saúde: desafios atuais. São Paulo: Hucitec, 2018. p. 68-84.

QUIJANO, A. Colonialidade do poder e classificação social. In: SANTOS, B. S.; MENESES, M. P. (Orgs.). Epistemologias do Sul. Coimbra: Almedina, 2009. p. 73-117.

SANTOS, B. S. O fim do império cognitivo: a afirmação das epistemologias do Sul. 1. ed. Belo Horizonte: Autêntica, 2019.

VASCONCELOS, E. M. Formar profissionais de saúde capazes de cuidar do florescer da vida. In: VASCONCELOS, E. M.; FROTA, L. H.; SIMON, E. (Orgs.). Perplexidade na universidade: vivências nos cursos de saúde. 2. ed. São Paulo: Hucitec, 2015. p. 265-308.

WALSH, C. Interculturalidad y (de)colonialidad: perspectivas críticas y políticas. Visão Global, Joaçaba, v. 15, n. 1-2, p. 61-74, jan./dez. 2012.

WALSH, C. Interculturalidad, Estado, Sociedad: luchas (de)coloniales de nuestra época. Quito: UASB; Ediciones Abya-Yala, 2009. 